\title{
Cardiovascular Magnetic Resonance in Right Heart and Pulmonary Circulation ${ }_{04}$ Disorders
}

Carla Contaldi, MD, PhD ${ }^{a, *}$, Francesco Capuano, $\mathrm{PhD}^{\mathrm{b}}$, Luigia Romano, $\mathrm{MD}^{\mathrm{c}}$, Brigida Ranieri, ${ }^{2}$, Francesco Ferrara, MD, PhD ${ }^{a}$, Gaetano Mirto ${ }^{\mathrm{e}}$,

Salvatore Regaf $\&$ bsangela Cocchia, MD ${ }^{g}$, Anna Agnese Stanziola, MD ${ }^{h}$, Ellen Ostenfield, $\mathrm{MD}, \mathrm{PhD}^{\mathrm{i}, 2}$, Santo Dellegrottaglie, $\mathrm{MD}, \mathrm{PhD}^{\mathrm{j}}$, Q6Q5 Eduardo Bossone, MD, PhD, FCCP, FESC ${ }^{g}$, Robert O. Bonow, MD, FAHA, FESC ${ }^{k}$ Q8Q6 Q109

\section{KEYWORDS}

- Cardiac magnetic resonance $\bullet$ Right heart and pulmonary circulation disorders $\bullet$ Diagnosis

- Prognosis • Therapeutic management

\section{KEY POINTS}

- Cardiac magnetic resonance (CMR) allows accurate multiplanar assessment of right ventricle (RV) volume, global and regional systolic function, tissue characterization, and evaluation of right heart and pulmonary artery blood flows.

- The aim of this paper is to review the role of CMR in RV pressure-overload and volume-overload disorders and RV cardiomyopathies.

- The clinical utility of CMR in diagnosis, prognosis, and therapeutic management of the right heart and pulmonary circulation disorders is discussed.

\section{INTRODUCTION}

Cardiac magnetic resonance (CMR) provides a noninvasive morphologic and functional assessment, tissue characterization, and blood flow evaluation of the right heart and pulmonary circulation.
Right heart and pulmonary circulation disorders are generally caused by right ventricle (RV) pressure overload, volume overload, and cardiomyopathy and they are associated with distinct clinical courses and therapeutic approaches, although they often may coexist. ${ }^{2}$

\footnotetext{
a Department of Cardiology, University Hospital of Salerno, Via Enrico de Marinis, Cava de' Tirreni, Salerno 84013, Italy; ${ }^{b}$ Department of Industrial Engineering, Federico II University of Naples, Via Claudio 21, Naples 80125, Italy; ' General and Emergency Radiology Division, A Cardarelli Hospital, Via Cardarelli 9, Naples

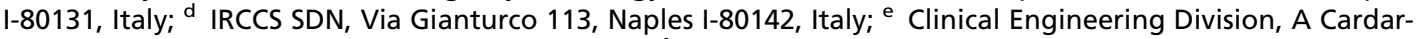
elli Hospital, Via Cardarelli 9, Naples I-80131, Italy; ${ }^{f}$ Medical School, Federico II University of Naples, Via Pansini 5, Naples I-80131, Italy; ${ }^{9}$ Cardiology Division, A Cardarelli Hospital, Via Cardarelli 9, Naples I-80131, Italy; h Department of Respiratory Diseases, Monaldi Hospital, University "Federico II", Via Leonardo Bianchi, Naples 80131, Italy; ' Department of Medical Imaging and Physiology, Cardiac Imaging, Skåne University Hospital, Entrégatan 7, Lund 222 42, Sweden; ' Division of Cardiology, Clinica Villa dei Fiori, C.so Italia 157, 80011, Acerra, Naples, Italy; ${ }^{k}$ Department of Medicine-Cardiology, Northwestern University Feinberg School of Medicine, 676 North St. Clair Street, Arkes Suite 2330, Chicago, IL 60611, USA

1 Present address: Via Ima 3, 83023 Lauro (AV), Italy.

2 Present address: Sö Ivegatan 19-BMC F12, Lund, Sweden.

* Corresponding author.

E-mail address: contaldi.carla@gmail.com
} 
This paper reviews CMR application in imaging of the right heart and pulmonary circulation and discusses its current and future application for the management of patients with right heart and pulmonary circulation disorders.

\section{THE NORMAL RIGHT HEART AND PULMONARY CIRCULATION}

The RV appears crescent shaped in cross-section, so it cannot be characterized using geometric assumptions. In normal conditions, the interventricular septum is concave toward the left ventricle (LV) throughout the cardiac cycle (Fig. 1). 2,3 The $\mathrm{RV}$ can be described in terms of the inlet region, the trabeculated apical myocardium and the infundibulum or RV outflow tract (RVOT). ${ }^{2,3}$ The RV free wall is thinner than the LV wall..,3 The superficial $\mathrm{RV}$ wall layer is composed of myocardial fibers arranged more circumferentially than in the LV and it is responsible for inward contraction. The subendocardial RV layer is composed of preferentially arranged longitudinal myocardial fibers that causes systolic contraction of the base toward the apex. Shortening of the RV is greater longitudinally ( $75 \%$ of $\mathrm{RV}$ contraction) than radially, and twisting and rotational movements do not contribute significantly to contraction. ${ }^{2,3}$ The RV and LV are closely interrelated through the septum, epicardial circumferential myocytes, and the pericardial space, which are the anatomic basis for biventricular functional interdependence. $\mathrm{RV}$ is more compliant of accommodating increased preload, but has heightened sensitivity to afterload change (it is unable to cope with brisk increments in pulmonary artery [PA] pressures). ${ }^{2,3}$

\section{THE ROLE OF CARDIAC MAGNETIC RESONANCE}

Strengths and weakness of imaging modalities in the evaluation of structure and function of right heart and pulmonary circulation unit are illustrated in Table 1. ${ }^{1,4-6}$
CMR is the gold standard modality for noninvasive RV imaging. It allows multiplanar imaging of the RV, gives accurate quantitative assessment of several parameters (ventricular volumes, myocardial mass, ejection fraction [EF], stroke volume [SV], and cardiac output [CO]), and qualitative assessment of $\mathrm{RV}$ regional function with a low intraobserver and interobserver variability and good interstudy reproducibility. ${ }^{5,6}$ CMR allows also tissue characterization and evaluation of vascular abnormalities. ${ }^{1,5,6}$ Limitations of CMR may include low availability, high cost, breath hold requirement, claustrophobia, safety in patients with ferromagnetic implants, and use of gadolinium in patients with severe chronic renal failure.

\section{CARDIAC MAGNETIC RESONANCE IMAGING PROTOCOL}

Routine CMR scans include cine, phase contrast $(\mathrm{PC})$, and postcontrast sequences. For cine imaging, balanced steady-state free precession (bSSFP) is the sequence of choice for assessment of LV and RV size and function due to its excellent contrast-to-noise ratio between cardiac structures and high reproducibility and reliability. Stacks of cardiac short-axis and transaxial images are acquired for a complete volumetric coverage of the $\mathrm{RV}^{7}$ Also, PC imaging of $\mathrm{PA}$, including main (MPA), right (RPA), and left (LPA), can be obtained to assess $P A$ hemodynamic variables and dimensions. Using this technique, pulmonary flow (QP) and systemic flow (QS) ratio and valve regurgitation severity can be quantified. Then, contrastenhanced magnetic resonance angiography (ceMRA) allows accurate visualization of central, lobar, and segmental pulmonary vessels. In patients for whom gadolinium is contraindicated, 3D whole-heart MRA (or 3D-SSFP) can be used instead. Finally, late gadolinium enhancement (LGE) imaging, obtained 10 to 15 min after administration of intravenous gadolinium contrast agent,
146

147

148

149

150

151

152

153

154

155

156

157

158

159

160

161

162

163

164

165

166

167

168

169

170

171

172

173

174

175

176

177

178

179

180

181

182

183

184

185

186

187

188 


\section{Table 1}

Relative strengths and weaknesses of different multimodality imaging techniques in the evaluation of structure and function of right heart and pulmonary circulation

\begin{tabular}{|c|c|c|c|c|}
\hline & Echo & CMR & CT & Nuclear Imaging \\
\hline Availability & ++++ & ++ & +++ & ++ \\
\hline Portability & ++++ & - & - & - \\
\hline Cost & Low & High & Medium & Medium \\
\hline Speed of acquisition & ++++ & ++ & ++++ & + \\
\hline Radiation risk & - & - & $+++^{a}$ & ++++ \\
\hline $\begin{array}{l}\text { Suitability for sick or } \\
\text { claustrophobic patients }\end{array}$ & ++++ & + & ++ & $+I-$ \\
\hline Contrast agents & $+/-$ & + & ++++ & - \\
\hline Temporal resolution & ++++ & +++ & ++ & $-{ }^{b}$ \\
\hline Spatial resolution & ++ & +++ & ++++ & + \\
\hline Right heart structure & +++ & ++++ & ++ & - \\
\hline Right ventricular function & +++ & ++++ & ++ & ++ \\
\hline Tissue characterization & + & ++++ & ++ & + \\
\hline Myocardial viability & + & ++++ & + & ++++ \\
\hline First-pass perfusion & ++ & ++++ & - & ++++ \\
\hline Coronary artery imaging & + & ++ & +++ & - \\
\hline $\begin{array}{l}\text { Assessment of pressure } \\
\text { gradients }\end{array}$ & ++++ & ++ & - & - \\
\hline Clinical application & $\begin{array}{l}\text { - Allows to assess right } \\
\text { heart structure, function, } \\
\text { and pressures at rest and } \\
\text { during exercise } \\
\text { - 2D echo can be used as a } \\
\text { screening tool } \\
\text { - 3D echo is more accurate } \\
\text { and reproducible in } \\
\text { evaluating RV size and } \\
\text { systolic function }\end{array}$ & $\begin{array}{l}\text { - Is the gold standard in } \\
\text { evaluating right heart } \\
\text { structure and function } \\
\text { - Allows tissue character- } \\
\text { ization and evaluation of } \\
\text { vascular abnormalities } \\
\text { - Ruling out underlying } \\
\text { CAD }\end{array}$ & $\begin{array}{l}\text { - Allows quantitative 3D } \\
\text { RV assessment and fatty } \\
\text { infiltration when CMR is } \\
\text { unavailable or unsuitable } \\
\text { - Ruling out underlying } \\
\text { CAD and lung disease } \\
\text { (interstitial, COPD, } \\
\text { CTEPH, cancer) }\end{array}$ & $\begin{array}{l}\text { - Allows assessment of } \\
\text { myocardial ischemia and } \\
\text { viability in underlying } \\
\text { suspected CAD }\end{array}$ \\
\hline
\end{tabular}




\begin{tabular}{|c|c|c|c|c|}
\hline \multicolumn{5}{|l|}{$\begin{array}{l}\text { Table } 1 \\
\text { (continued) }\end{array}$} \\
\hline & Echo & CMR & СT & Nuclear Imaging \\
\hline Limitations & $\begin{array}{l}\text { - Highly operator } \\
\text { dependent } \\
\text { - Inadequate imaging } \\
\text { window } \\
\text { - Limited evaluation of } \\
\text { right ventricle and pul- } \\
\text { monary circulation }\end{array}$ & $\begin{array}{l}\text { - Safety in patients with } \\
\text { ferromagnetic implants } \\
\text { - Use of gadolinium in pa- } \\
\text { tients with severe chronic } \\
\text { renal failure } \\
\text { - Breath holding } \\
\text { - No portability } \\
\text { - Higher cost } \\
\text { - Claustrophobia }\end{array}$ & $\begin{array}{l}\text { - Radiation exposure } \\
\text { - Use of iodinated contrast } \\
\text { - No portability } \\
\text { - Higher cost } \\
\text { - Claustrophobia }\end{array}$ & $\begin{array}{l}\text { - Radiation exposure } \\
\text { - No portability } \\
\text { - Low spatial resolution } \\
\text { - Long scanning time } \\
\text { - Significantly higher cost }\end{array}$ \\
\hline
\end{tabular}

+ denotes a positive remark and - denotes a negative remark. The number of signs indicates the estimated potential value.

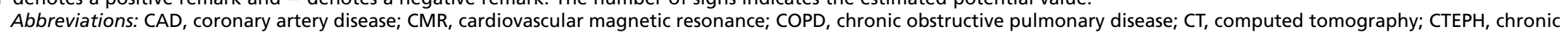
thromboembolic pulmonary hypertension; RV, right ventricle.

a Radiation risk is significantly higher when the cine ventricular function and fist pass perfusion are performed.

b Temporal resolution for nuclear techniques is variable and depends on the radiotracer and counts.

Modified from Zhou X, Ferrara F, Contaldi C, et al. Right ventricular size and function in chronic heart failure: not to be forgotten. Heart Fail Clin 2019;15:210; with permission. 
permits visualization and quantification of myocardial reparative fibrosis (scar). ${ }^{5,6}$ When indicated, other optional CMR techniques can be used (Table 2).

\section{PRESSURE-OVERLOAD DISORDERS}

RV pressure overload leads to RV hypertrophy, predominantly end-systolic and early-diastolic flattening of the interventricular septum and "D shape" of the LV in systole (see Fig. 1). In the setting of chronic pressure overload, the RV initially responds with preserved volumes and function and compensatory "concentric" hypertrophy, successively, with "eccentric" hypertrophy, progressive RV dilatation, dyssynchrony, fibrosis, and reduced $\mathrm{CO}$, leading to deterioration of exercise capacity and ultimately clinical decompensation. The RV becomes less dependent on longitudinal shortening. ${ }^{2}$ The most common chronic RV pressure-overload disorders are described in the following paragraphs.

\begin{tabular}{|c|c|}
\hline Technique & Information \\
\hline CINE (b-SSFP) & $\begin{array}{l}\text { - RV and LV dimension, mass, } \\
\text { regional and global } \\
\text { function } \\
\text { - Atrial dimension } \\
\text { - Interventricular septal } \\
\text { changes } \\
\text { - MPA, LPA, RPA dimension } \\
\text { - Pulmonary valve direct } \\
\text { planimetry } \\
\end{array}$ \\
\hline Phase contrast & $\begin{array}{l}\text { - QP and QS } \\
\text { - Cardiac output and PA flow } \\
\text { profile } \\
\text { - Pulmonary valve direct re- } \\
\text { gurgitant volume } \\
\text { - PA stiffness and pulsatility } \\
\end{array}$ \\
\hline LGE & $\begin{array}{l}\text { - Ventricular myocardial } \\
\text { reparative fibrosis } \\
\text { - Ventricular myocardial } \\
\text { microvascular obstruction }\end{array}$ \\
\hline ce-MRA & $\begin{array}{l}\text { - Vascular anatomy } \\
\text { - Pulmonary perfusion }\end{array}$ \\
\hline 3D whole-heart MRA or 3D SSFP & - Vascular anatomy \\
\hline $\begin{array}{l}\text { Black blood images with and } \\
\text { without fat suppression } \\
\text { (when indicated) }\end{array}$ & - Fat infiltration \\
\hline T2w STIR (when indicated) & $\begin{array}{l}\text { - Myocardial edema } \\
\text { - Myocardial hemorrhage }\end{array}$ \\
\hline T1-Mapping (optional) & - Diffuse myocardial fibrosis \\
\hline T2-Mapping (optional) & - Myocardial edema \\
\hline $\begin{array}{l}\text { Tagging technique/feature } \\
\text { tracking (optional) }\end{array}$ & $\begin{array}{l}\text { - Strain and strain rate } \\
\text { analysis } \\
\text { - Interventricular asynchrony } \\
\end{array}$ \\
\hline 4D Flow (optional) & $\begin{array}{l}\text { - RV and PA 3D flow patterns } \\
\text { - PA vortex } \\
\text { - PA wall shear stress and en- } \\
\text { ergy loss } \\
\text { - RV kinetic energy work } \\
\text { density }\end{array}$ \\
\hline
\end{tabular}

Abbreviations: b-SSFP, balanced steady-state free precession; ce-MRA, contrast-enhanced magnetic resonance angiography; LPA, left pulmonary artery; LV, left ventricle; MPA, main pulmonary artery; PA, pulmonary artery; QP, pulmonary flow; QS, systemic flow; RPA, right pulmonary artery; RV, right ventricle. 


\section{Pulmonary Hypertension}

Pulmonary hypertension $(\mathrm{PH})$ is a pathophysiological condition defined as an increase in mean PA pressure $(\mathrm{mPAP}) \geq 25 \mathrm{~mm} \mathrm{Hg}$ at rest by right heart catheterization (RHC). It is hemodynamically categorized into 2 groups: precapillary and postcapillary. In particular, pulmonary arterial hypertension $(\mathrm{PAH})$ is defined as a group of precapillary $\mathrm{PH}$ and pulmonary vascular resistance (PVR) $>3$ Wood units in absence of the other causes of precapillary $\mathrm{PH}^{8}$ The $\mathrm{PH}$ diagnostic algorithm with the specific role of noninvasive imaging is illustrated in Fig. 2.

\section{ROLE OF CARDIAC MAGNETIC RESONANCE IN PULMONARY HYPERTENSION Diagnosis and Cause}

The most accurate tools by cine-CMR, for the identification of $\mathrm{PH}$ are the ventricular mass index, which expresses the degree of chronic RV pressure overload, ${ }^{9}$ the increased area and thickness of basal segment of the septomarginal band, ${ }^{10}$ and the interventricular septum curvature ratio, which is an accurate and reproducible index of $\mathrm{RV}$ systolic pressure. ${ }^{11}$ Cine-CMR also allows visualization of the degree of flattening of the interventricular septum and a "D-shaped" LV in the presence of severe $\mathrm{PH}$ (see Fig. 1). ${ }^{2}$

Using 2D-PC, peak PA systolic pressure can be derived using the modified Bernoulli equation and reduced pulmonary average velocities, blood flow, and distensibility can be evaluated in patients with $\mathrm{PH}^{12}$ Average velocity in the MPA has a high degree of reliability in detecting $\mathrm{PH}$ and it has also a strong inverse correlation with PAP and PVR. ${ }^{13}$ Relative area change (RAC) can be used as a marker of MPA stiffness. RAC increases early in $\mathrm{PH}$ and may detect exerciseinduced $\mathrm{PH}$ before overt pressure increases occur at rest. ${ }^{14}$

LGE-CMR shows areas of LGE induced by chronic ventricular overload frequently in the RV insertion points of the interventricular septum corresponding to higher fiber stress zones (Fig. 3, Table 3). ${ }^{15,16}$ However, no single CMR parameter can exclude $\mathrm{PH}$.

In identifying the cause of $\mathrm{PH}$ due to left heart disease, CMR can quantify LV volumes and EF accurately, identify valvular heart disease, and differentiate between ischemic and nonischemic cardiomyopathy by the pattern of LGE. ${ }^{1}$ If coronary artery disease is suspected, stress perfusion CMR can evaluate LV and RV function, perfusion, and myocardial scar. In chronic thromboembolic $\mathrm{PH}$, ce-MRA may allow accurate visualization of the lobar and segmental pulmonary vessels, and 3D whole-heart MRA may measure regional changes in segmental or subsegmental lung perfusion. ${ }^{1,5,6}$ In patients with PAH secondary to congenital heart disease, CMR provides complete evaluation of cardiac and extracardiac structures and may be useful in diagnosis, treatment planning and followup $^{5,6}$ (see Fig. 2).

\section{Risk Stratification, Prognosis, and Monitor Treatment Efficacy}

Cine-CMR is useful in clinical management. An increased RV end-diastolic volume (EDV) indexed to body surface area (RV EDVI) is the most reliable marker for RV failure and a valuable predictor of poor survival. The correlation of RV dilatation to mortality is stronger than RV hypertrophy ${ }^{17}$; however, ventricular mass index has been suggested to be a predictor of decreased survival. ${ }^{18} \mathrm{RV} E F$ is the strongest predictor of mortality ${ }^{19,20}$ and severity of right atrial (RA) volume dilation is associated with disease progression and prognosis. ${ }^{21,22}$ PC-CMR measurements reflecting stiffness of the proximal pulmonary vasculature ${ }^{23}$ are independent predictors of outcome. LGE at the RV insertion point seems to be associated with more advanced $\mathrm{PH}$, especially if the LGE is including the septum (Table 4). ${ }^{16,24}$

For the monitoring of drug therapy in patients with $\mathrm{PH}, \mathrm{RV}$ mass and RV EF by cine-CMR might be used. ${ }^{19,25}$ In patients with $\mathrm{PH}$, the addition of sildenafil to bosentan therapy reduces RV mass and this effect is associated with improvements of symptoms and NTproBNP ${ }^{25}$; after 1 year of therapy, reduced RV $E F$ is associated with poor outcome, even in patients with $\mathrm{PAH}$ with PVR improvement ${ }^{19}$ (Table 5).

\section{NOVEL CARDIAC MAGNETIC RESONANCE TECHNIQUES IN PULMONARY HYPERTENSION \\ T1-Mapping}

T1-mapping has been developed to quantify diffuse myocardial fibrosis directly measuring the T1 relaxation times. Native T1 reflects both the intracellular and extracellular compartments. ${ }^{26}$ The extracellular contrast volume (ECV) (calculated taking into account myocardial and blood T1 values precontrast and postcontrast) provides a direct measure of the of myocardium occupied by extracellular space. ${ }^{26}$ 
Symptoms/Signs/History suggestive of $\mathrm{PH}$ Clinical Assessment - ECG - Chest X-ray - Routine Biochemistry - BNP

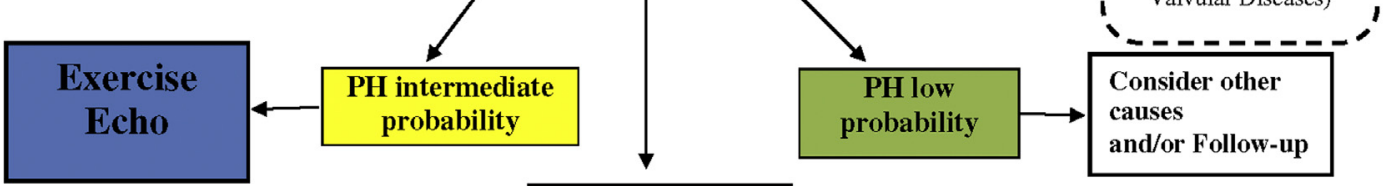

TRV and additional indirect signs suggestive of PH

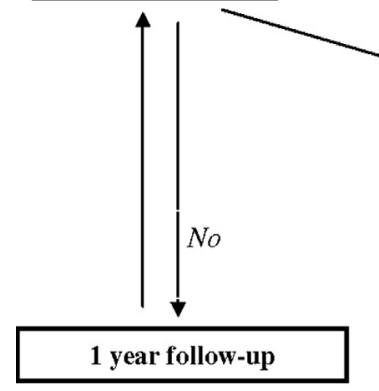

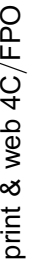

PAH diagnosis: mean PAP $\geq 25 \mathrm{~mm} \mathrm{Hg}$; Pulmonary Capillary Wedge Pressure $\leq 15 \mathrm{~mm} \mathrm{Hg}$, PVR $>3 \mathrm{WU}$ 
LGE at RV insertion points of the septum in PH

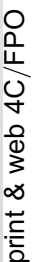

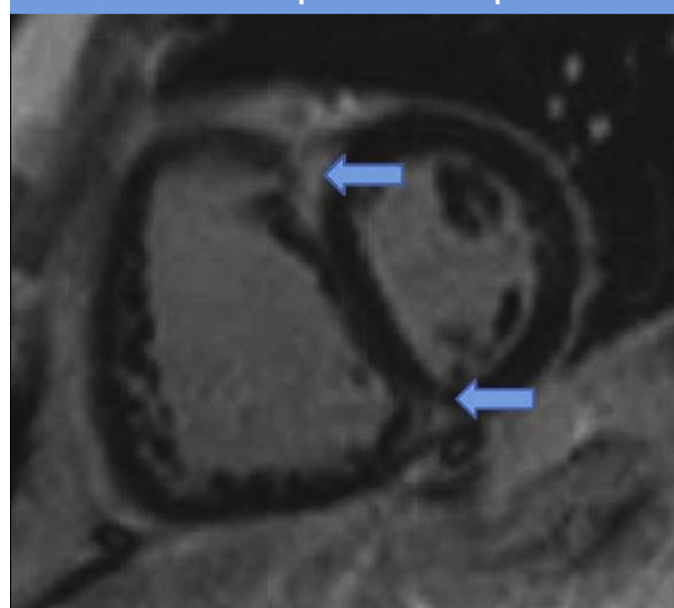

Fig. 3. An example of LGE (blue arrows) at RV insertion point spreading into the septum in a patient with $\mathrm{PH}$. LGE, late gadolinium enhancement; $\mathrm{PH}$, pulmonary hypertension; RV, right ventricle.
In patients with precapillary $\mathrm{PH}$, native $\mathrm{T} 1$ values of RV insertion points are significantly increased and are related to $\mathrm{PH}$ severity. ${ }^{27}$ In patients with $\mathrm{PH}, \mathrm{RV} \mathrm{ECV}$ is increased. Both native $\mathrm{T} 1$ and $E C V$ values at $R V$ insertion points are increased and show significant correlations with pulmonary hemodynamics, RV arterial coupling, and RV performance. ECV is increased before overt RV systolic dysfunction. ${ }^{28} \mathrm{ECV}$ is useful in detecting myocardial involvement in early stages of $\mathrm{PH}$, can guide management, and serve as a therapeutic target. However, caution should be emphasized in interpreting $\mathrm{T} 1$ values in the thin and highly trabeculated RV free wall, as partial volume effects and inclusion of fat or blood (erroneously, however easily done) in the region of interest are major caveats to the measurements.

\section{Strain Analysis}

Fast strain encoded (SENC) is a through-plane CMR-tagging technique that allows direct
830

831

832

833

834

835

836

837

838

839

840

841

842

843

844

845

846

847

848

849

850

851

852

853

854

855

856

857

858

859

860

861

862

863

864

865

866

867

868

869

870

871

872

873

874

875 


\begin{tabular}{|c|c|c|c|}
\hline Prognostic CMR Variable & Cutoff Value & Comment & Reference \\
\hline \multicolumn{4}{|l|}{ Cine-CMR } \\
\hline RV EDVI & $\geq 84 \mathrm{~mL} / \mathrm{m}^{2}$ & $\begin{array}{l}\text { Predictor of RV failure } \\
\text { and mortality }\end{array}$ & $\begin{array}{l}\text { Van Wolferen et al, }{ }^{17} \\
2007\end{array}$ \\
\hline RV EF & $\leq 35 \%$ & $\begin{array}{l}\text { Predictor of poor } \\
\text { outcome and mortality }\end{array}$ & $\begin{array}{l}\text { van de Veerdonk et al, } \\
2011\end{array}$ \\
\hline $\begin{array}{l}\text { Ventricular mass index } \\
\text { (RV end-diastolic } \\
\text { mass/LV end-diastolic } \\
\text { mass) }\end{array}$ & $\geq 0.7$ & $\begin{array}{l}\text { Predictor of decreased 2-y } \\
\text { survival }\end{array}$ & Hagger et al, ${ }^{18} 2009$ \\
\hline RA volume & Increased & $\begin{array}{l}\text { Associated with disease } \\
\text { progression and } \\
\text { prognosis }\end{array}$ & Sato et al, ${ }^{21} 2013$ \\
\hline \multicolumn{4}{|l|}{ PC-CMR } \\
\hline $\begin{array}{l}\text { Pulmonary artery } \\
\text { relative area change }\end{array}$ & $\leq 16 \%$ & $\begin{array}{l}\text { Predictor of poor } \\
\text { outcome and mortality }\end{array}$ & Gan et al, $^{23} 2007$ \\
\hline SVI & $\leq 25 \mathrm{~mL} / \mathrm{m}^{2}$ & $\begin{array}{l}\text { Predictor of RV failure } \\
\text { and mortality }\end{array}$ & $\begin{array}{l}\text { Van Wolferen et al, }{ }^{17} \\
2007\end{array}$ \\
\hline \multicolumn{4}{|l|}{ LGE-CMR } \\
\hline RV insertion site LGE & Present & $\begin{array}{l}\text { Predictor of poor } \\
\text { prognosis }\end{array}$ & Freed et al, ${ }^{16} 2012$ \\
\hline \multicolumn{4}{|l|}{ Feature tracking CMR } \\
\hline RV GLS and GLSR & Reduced & $\begin{array}{l}\text { Associated with poor } \\
\text { outcome }\end{array}$ & $\begin{array}{l}\text { Menezes de Siqueira } \\
\text { et al, }{ }^{30} 2016\end{array}$ \\
\hline RV GCSR & $>-0.8 \mathrm{~s}^{-1}$ & Predictor of events & $\begin{array}{l}\text { Menezes de Siqueira } \\
\text { et } \mathrm{al}^{30} 2016\end{array}$ \\
\hline LV GLS & $>-14.2 \%$ & $\begin{array}{l}\text { Predictor of poor } \\
\text { outcome and mortality } \\
\text { in precapillary } \mathrm{PH}\end{array}$ & $\begin{array}{l}\text { Padervinskienè et al, } \\
2019\end{array}$ \\
\hline
\end{tabular}

longitudinal strain; GLSR, global longitudinal strain rate; LV, left ventricle; RV, right ventricle; SVI, stroke volume index.

measurement of regional function by using a freebreathing single-heartbeat real-time acquisition. It allows direct measurement of longitudinal strain by using short-axis images. Fast SENC identifies significantly reduced RV longitudinal contractility at basal-mid anterior septal insertions and mid anterior RV wall in patients with PAH with normal global RV function. ${ }^{29}$

Feature tracking (FT) is a novel method that allows quantification of myocardial deformation from cine-CMR images. Patients with $\mathrm{PH}$ show significant reductions in global longitudinal strain (GLS), global circumferential strain (GCS), global longitudinal strain rate (GLSR), and global circumferential strain rate (GCSR). GLS, GLSR, and GCSR are independently associated with outcome. ${ }^{30}$ LV GLS also shows correlation with $\mathrm{RV}$ dysfunction and is associated with poor clinical outcome and mortality. ${ }^{31}$ Therefore, in $\mathrm{PH}$, quantification of RV and LV strain by FT-CMR is feasible, correlates with disease severity, and is independently associated with poor outcome (see Table 4).

\section{Blood Flow Imaging}

$4 D$ Flow $C M R$ is an evolving imaging technique that provides in-vivo assessment of 3-directional blood flow within 3D vascular structures throughout the cardiac cycle. RV volume, function, and mass can be quantified with interobserver agreement comparable with cine-CMR SSFP sequences. $^{32}$ Whole-heart 4D flow CMR enables detection and visualization of both normal and abnormal right heart flow patterns. In patients with $\mathrm{PH}$, vortex of blood flow in the MPA from 4D flow CMR is present and the vortex duration has been related with MPAP (Fig. 4, see Table 3). ${ }^{33}$ Vorticity is decreased in the RPA of patients with $\mathrm{PH}$ and it correlates with an increase in PVR. ${ }^{34}$ 4D flow CMR can also estimate wall shear stress (WSS), a measure of viscous hemodynamic forces 


\begin{tabular}{|c|c|c|c|c|c|c|c|}
\hline $\begin{array}{l}\text { Pulmonary } \\
\text { Hypertension }\end{array}$ & \begin{tabular}{|l} 
Pulmonary \\
Valve Stenosis
\end{tabular} & $\begin{array}{l}\text { Tricuspid } \\
\text { Valve } \\
\text { Regurgitation }\end{array}$ & \begin{tabular}{|l} 
Pulmonary \\
Valve \\
Regurgitation
\end{tabular} & \begin{tabular}{|l} 
Systemic-to- \\
Pulmonary \\
Shunt
\end{tabular} & RV Infarction & $\begin{array}{l}\text { Arrhythmogenic } \\
\text { Cardiomyopathy }\end{array}$ & $\begin{array}{l}\text { Other Nonischemic } \\
\text { Cardiomyopathies } \\
\text { (Hypertrophy, } \\
\text { Dilated, } \\
\text { Noncompaction, } \\
\text { Tako-Tsubo, } \\
\text { Amyloidosis, } \\
\text { Sarcoidosis, } \\
\text { Myocarditis) }\end{array}$ \\
\hline Diagnosis & $\begin{array}{l}\text { Accurate } \\
\text { assessment } \\
\text { of valve stenosis } \\
\text { severity: } \\
\text { prefer planimetry }\end{array}$ & \begin{tabular}{|l|} 
Accurate \\
assessment of \\
valve \\
regurgitation \\
severity: prefer \\
indirect method
\end{tabular} & $\begin{array}{l}\text { Accurate } \\
\text { assessment of } \\
\text { valve } \\
\text { regurgitation } \\
\text { severity: prefer } \\
\text { direct method }\end{array}$ & $\begin{array}{l}\text { Size, location, } \\
\text { and number of } \\
\text { communications } \\
\text { between } \\
\text { pulmonary and } \\
\text { systemic } \\
\text { circulations: } \\
\text { intra- and } \\
\text { extracardiac } \\
\end{array}$ & $\begin{array}{l}\text { Evaluation of } \\
\text { RV ischemic } \\
\text { injury: } \\
\text { - RV anatomic } \\
\text { and functional } \\
\text { assessment } \\
\text { - Tissue } \\
\text { characterization }\end{array}$ & Early diagnosis & $\begin{array}{l}\text { Early RV/LV } \\
\text { involvement }\end{array}$ \\
\hline Cause & \begin{tabular}{|c} 
Hemodynamic \\
consequences
\end{tabular} & $\begin{array}{c}\text { Hemodynamic } \\
\text { consequences }\end{array}$ & $\begin{array}{c}\text { Hemodynamic } \\
\text { consequences }\end{array}$ & $\begin{array}{c}\text { Hemodynamic } \\
\text { consequences }\end{array}$ & $\begin{array}{l}\text { RV infarction } \\
\text { complications }\end{array}$ & $\begin{array}{l}\text { Disease } \\
\text { classification }\end{array}$ & Prognosis \\
\hline Prognosis & $\begin{array}{l}\text { Identify sub- or } \\
\text { supravalvular } \\
\text { stenosis }\end{array}$ & Prognosis & Prognosis & $\begin{array}{l}\text { Accurate QP/QS } \\
\text { ratio } \\
\text { quantification }\end{array}$ & Prognosis & Prognosis & $\begin{array}{l}\text { Detection of } \\
\text { eventual } \\
\text { associated } \\
\text { systemic } \\
\text { alterations, ie, } \\
\text { enlarged lymph } \\
\text { nodes } \\
\end{array}$ \\
\hline $\begin{array}{l}\text { Monitor } \\
\text { treatment } \\
\text { efficacy }\end{array}$ & $\begin{array}{l}\text { Secondary PA } \\
\text { dilatation }\end{array}$ & & $\begin{array}{l}\text { Timing of } \\
\text { reintervention: } \\
\text { in previous } \\
\text { surgery for } \\
\text { congenital heart } \\
\text { diseases }\end{array}$ & $\begin{array}{c}\text { Atrial septal } \\
\text { defect rims }\end{array}$ & & $\begin{array}{l}\text { Follow-up in } \\
\text { definite, } \\
\text { borderline, or } \\
\text { possible } \\
\text { arrhythmogenic } \\
\text { cardiomyopathy }\end{array}$ & \\
\hline
\end{tabular}




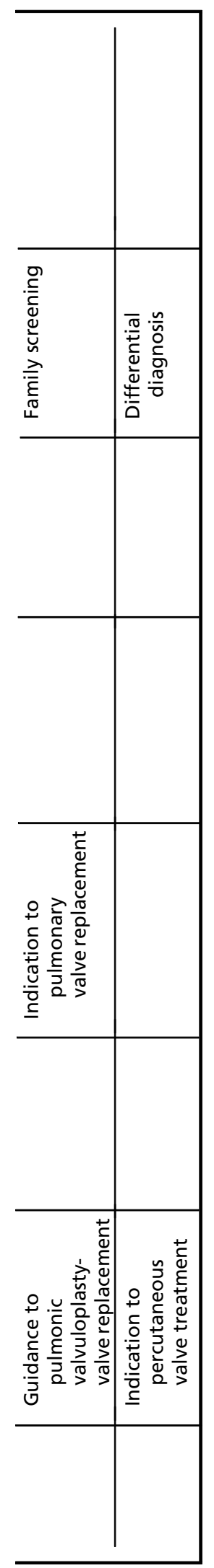




\section{Vortex of Blood Flow in MPA}

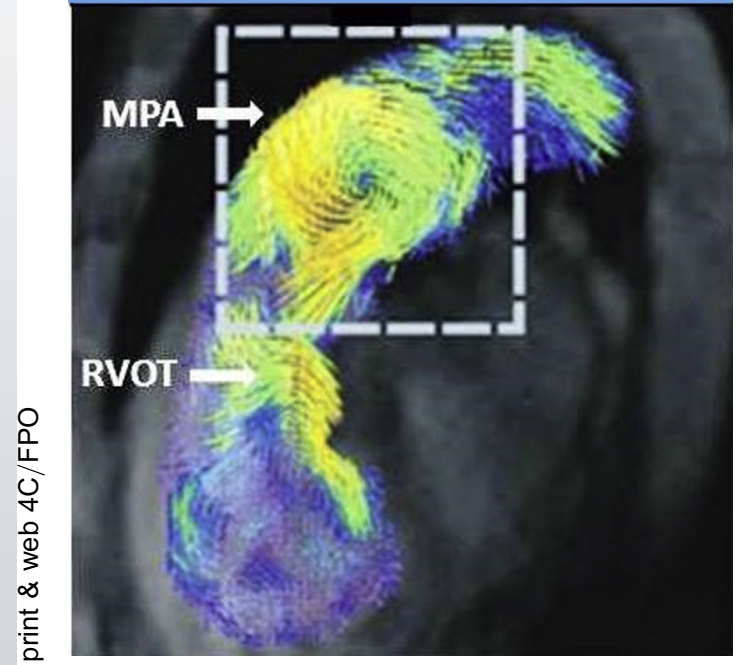

Fig. 4. An example of a vortex of blood flow in the MPA in a patient with PH by 4D flow CMR. CMR, cardiac magnetic resonance; MPA, main pulmonary artery; $\mathrm{PH}$, pulmonary hypertension.

acting on the vessel walls (risk factor of endothelial degeneration) and energy loss (EL), the energy dissipation caused by abnormal 3D blood flow (associated with high cardiac workload) in aortic disease. ${ }^{35} \mathrm{EL}$ is a possible predictor of heart failure. ${ }^{36}$ In patients with $\mathrm{PH}, 4 \mathrm{D}$ flow CMR at the MPA, RPA, and LPA shows significantly lower WSS, independent of the 4D flow CMR acquisition strategy. ${ }^{37}$ In addition, PA WSS is reduced in both children and adults with $\mathrm{PAH}$ associated with the degree of vessel dilation and stiffness. EL, instead, is increased in PAH without difference between adults and pediatric patients. ${ }^{38}$ In patients with $\mathrm{PAH}$, increase in RV kinetic energy work density and in PA percent EL seem to be promising markers for RV dysfunction. ${ }^{39}$

Computational fluid dynamics modeling, is another novel technology that generates equations of fluid dynamics in a computer using patient-specific vascular or heart chambers geometries and physiologic flow or pressure conditions. The geometries are reconstructed from segmentation of CMR or computed tomography (CT) images (Fig. 5). This technique has high temporal and spatial resolution and can also be used to reproduce the virtual flow that would be realized in hypothetical postsurgical conditions, therefore adding predictive capabilities to modern flow imaging. ${ }^{40}$ A CFD combined with CMR study has demonstrated for the first time that WSS is altered in $\mathrm{PAH}$, showing reduced WSS in the proximal PAs, as reported successively by 4D flow CMR. ${ }^{41}$ The prognostic value of these novel technologies for blood flow imaging remain to be proven; however, in the future they could offer a noninvasive alternative to $\mathrm{RHC}$ and could help in early detection of $\mathrm{PH}$.

\section{FUTURE PERSPECTIVES OF CARDIAC MAGNETIC RESONANCE IN PULMONARY HYPERTENSION}

\section{Exercise Cardiac Magnetic Resonance}

CMR during exercise permits highly reproducible and accurate measurements of RV volumes and function, and $\mathrm{CO}$ is comparable with that obtained by the direct Fick method. ${ }^{42}$ Assessment of RV function with CMR during exercise stratifies patients with PAH currently perceived as having a low risk of mortality into different degrees of RV inotropic reserve. Reduced RV SV during exercise CMR is a plausible marker of increased risk of decompensation, possibly warranting targeted therapy intensification to restore RV functional reserve. ${ }^{43}$

CMR during exercise is currently performed in very few centers because of difficulties in running adequate exercise sessions in the magnetic resonance environment.

\section{Cardiac Magnetic Resonance-Guided Right Heart Catheterization}

CMR-guided RHC (CMR-RHC) can combine the benefits of CMR and invasive cardiac catheterization.

CMR-RHC, using passive catheters, is an attractive modality for comprehensive hemodynamic characterization of cardiovascular conditions, such as PAH. After baseline CMR for cardiac function, transfemoral catheters are navigated into the superior vena cava (SVC), and thereafter from the right atrium into the RV and one or both pulmonary arteries. Patients with suspected PAH can be screened using first-pass contrast lung perfusion. Procedure time increases with worsening PAH. ${ }^{44,45}$ CMR-RHC applications are still in the primordial phase of clinical application, with few advanced centers equipped with hybrid-invasive CMR facilities. However, in the future CMR-RHC might be incorporated into routine clinical practice for the investigation of $\mathrm{PAH}$.

\section{Pulmonary valve stenosis}

Pulmonary valve stenosis (PS) is another cause of RV pressure overload and it is usually an isolated congenital abnormality but may be associated with other conditions (tetralogy of Fallot, 


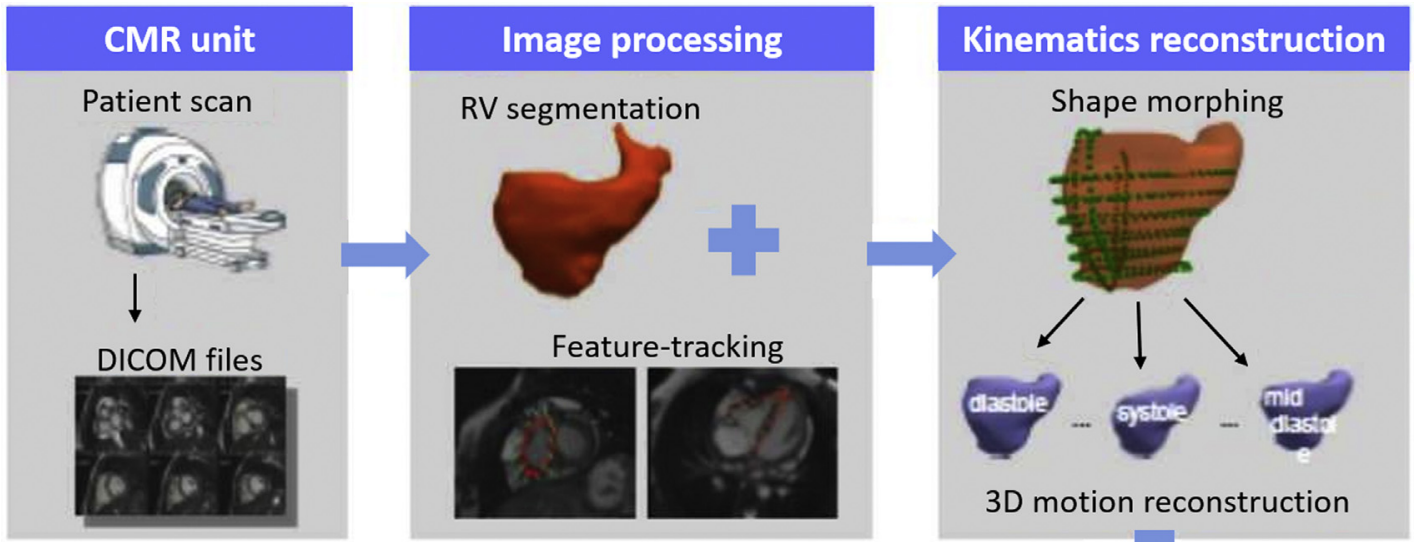

\section{CFD unit}

Numerical simulations
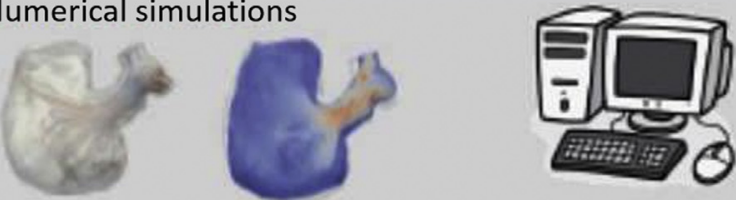

Output: flow features (e.g., vortices, helical flow), regional RV velocity and pressure, RV kinetic energy, vorticity, power losses, hemodynamic forces, ...

Fig. 5. A workflow from clinical imaging to numerical simulation of RV flow using CFD. (1) Acquisition of cineCMR SSFP images; (2) FT-CMR to automatically extract the time evolution of the RV endocardium and a fine 3D triangulated surface mesh of the geometry of the RV obtained through a segmentation process; (3) reconstruction of 3D RV motion using an image registration technique; (4) numerical simulations performed using CFD to solve the flow equations inside the previously computed moving geometry. CFD, computational fluid dynamics; CMR, cardiac magnetic resonance; FT-CMR, feature tracking cardiac magnetic resonance; RV, right ventricle; SSFP, steady-state free precession.

congenital rubella, and Noonan syndrome). PS may be secondary to carcinoid syndrome, rheumatic heart disease, thrombus, or cardiac surgery. PS is also associated with secondary dilation of MPA and LPA (less so the RPA) and with abnormalities of the structure of PA wall. ${ }^{46,47}$

\section{ROLE OF CARDIAC MAGNETIC RESONANCE IN PULMONARY VALVE STENOSIS}

Imaging the pulmonary valve requires an RVOT view and potentially a second view perpendicular to this plane. ${ }^{46-48}$ Cine-CMR shows doming of the leaflets, a high-velocity jet across the pulmonary valve and subvalvular or supravalvular stenosis. Short-axis cine imaging through the valve tips in systole provides direct planimetry of the valve orifice for accurate determination of anatomic orifice area. Multiple parallel thin slices may be helpful to locate the optimal slice. Cine-CMR can also quantify the hemodynamic consequences of PS. ${ }^{46,48}$ PC-CMR quantifies the peak velocity and the peak gradient is calculated using the modified Bernoulli equation. ${ }^{48}$ CMR can also provide a functional/effective orifice area (similar to the continuity equation by echocardiography), but direct planimetry is usually more reliable. ${ }^{47} \mathrm{CMR}$ can be useful to select patients eligible for percutaneous valve replacement. Valvuloplasty and valve replacement may be performed under CMR guidance (see Table 5). ${ }^{47}$

\section{VOLUME-OVERLOAD DISORDERS}

$\mathrm{RV}$ volume overload leads to RV dilatation and hypertrophy with increased free wall mass but preserved thickness and predominantly diastolic leftward septal shift with "D shape" of LV in diastole (see Fig. 1). In the setting of chronic volume overload, RV contractility remains preserved for long time periods, although contractile reserve may be compromised. ${ }^{2,3}$ The most common RV 
volume-overload disorders $\mathrm{s}^{2,3,48-51}$ are listed in Table 6.

\section{ROLE OF CARDIAC MAGNETIC RESONANCE IN VOLUME-OVERLOAD CONDITIONS Tricuspid Valve Regurgitation}

CMR can provide accurate assessment of tricuspid valve regurgitation (TR) severity and its secondary hemodynamic consequences and also identify RV dysfunction. Standard long-axis cine-CMR views with additional thin image slices positioned perpendicular to the leaflet sections may help to visualize the detailed anatomy/function. PC-CMR in-plane is helpful to identify the regurgitant jet. CMR allows quantitation of regurgitant volume and regurgitant fraction. ${ }^{48}$ The regurgitant volume is usually calculated indirectly, subtracting the flow volume by PC-CMR in the MPA from the SV obtained by cine-CMRderived RV volume measurements. Direct measurement of regurgitant flow at the valve is feasible but difficult due to mobile valve leaflets and high-velocity jets. An increased RV EDV by cine-CMR can predict RV dysfunction at followup $^{48-50}$ (see Table 5).

Table 6

Definition and classification of the most common right ventricle volume-overload disorders

\begin{tabular}{|c|c|c|c|c|}
\hline & \multirow[b]{2}{*}{$\begin{array}{l}\text { Tricuspid Valve } \\
\text { Regurgitation }\end{array}$} & \multirow[b]{2}{*}{$\begin{array}{l}\text { Pulmonary Valve } \\
\text { Regurgitation }\end{array}$} & \multicolumn{2}{|c|}{ Systemic-to-Pulmonary Shunt } \\
\hline & & & $\begin{array}{l}\text { Atrial Septal } \\
\text { Defect (ASD) }\end{array}$ & $\begin{array}{l}\text { Partial Anomalous } \\
\text { Pulmonary Vein } \\
\text { Drainage (PAPVC) }\end{array}$ \\
\hline Definition & $\begin{array}{l}\text { Blood flows back } \\
\text { through the } \\
\text { tricuspid valve } \\
\text { Tricuspid valve } \\
\text { complex: large } \\
\text { tricuspid } \\
\text { annulus, } 3 \\
\text { leaflets (anterior, } \\
\text { posterior, and } \\
\text { septal), 3 } \\
\text { independent } \\
\text { papillary } \\
\text { muscles, and } \\
\text { chordae } \\
\text { tendineae }\end{array}$ & $\begin{array}{l}\text { Blood flows back } \\
\text { through the } \\
\text { pulmonary valve } \\
\text { Pulmonary valve: } 3 \\
\text { semilunar } \\
\text { leaflets (anterior, } \\
\text { left, and right) }\end{array}$ & $\begin{array}{l}\text { Defect in the } \\
\text { interatrial } \\
\text { septum }\end{array}$ & $\begin{array}{l}\text { Anomalous } \\
\text { connection of } 1 \\
\text { or more } \\
\text { pulmonary veins } \\
\text { to the systemic } \\
\text { venous system }\end{array}$ \\
\hline Classification & $\begin{array}{l}\text { Primary anatomic } \\
\text { valvular } \\
\text { problems: } \\
\text { - latrogenic } \\
\text { - Endocarditis } \\
\text { - Rheumatic valve } \\
\text { disease } \\
\text { - Carcinoid } \\
\text { - Congenital heart } \\
\text { disease (ie, Eb- } \\
\text { stein anomaly) } \\
\text { Functional (more } \\
\text { common): } \\
\text { - Annular dilata- } \\
\text { tion due to RA } \\
\text { and/or RV dila- } \\
\text { tation and papil- } \\
\text { lary muscle } \\
\text { displacement }\end{array}$ & $\begin{array}{l}\text { Native valve (rare) } \\
\text { Primary anatomic } \\
\text { problems: } \\
\text { - Endocarditis } \\
\text { - Carcinoid } \\
\text { Secondary to: } \\
\text { - Surgical valvot- } \\
\text { omy/valvectomy } \\
\text { or balloon pul- } \\
\text { monary valvulo- } \\
\text { plasty for } \\
\text { pulmonary ste- } \\
\text { nosis (eg, tetral- } \\
\text { ogy of Fallot) } \\
\text { Functional: } \\
\text { - PA dilatation } \\
\text { - Severe PAH }\end{array}$ & $\begin{array}{l}\text { Ostium secundum } \\
(80 \%) \\
\text { Ostium primum } \\
(15 \%): \pm \\
\text { atrioventricular } \\
\text { valve defects } \\
\text { Sinus venous }(5 \%) \text { : } \\
\text { - Near the SVC } \\
\text { - } \pm \text { PAPVC (ie, up- } \\
\text { per right PV in } \\
\text { SVC or RA) } \\
\text { Coronary sinus } \\
(<1 \%)\end{array}$ & $\begin{array}{l}\text { The first most } \\
\text { common type: } \\
\text { - Right upper and } \\
\text { middle PV into } \\
\text { SVC } \\
\text { - Often + superior } \\
\text { sinus venosus } \\
\text { ASD } \\
\text { The second most } \\
\text { common type: } \\
\text { - Left upper PV } \\
\text { into the left } \\
\text { innominate vein } \\
\text { via a vertical vein } \\
\text { Scimitar syndrome: } \\
\text { - All right-sided } \\
\text { PVs into RA, IVC } \\
\text { or hepatic veins }\end{array}$ \\
\hline
\end{tabular}

Abbreviations: IVC, inferior vena cava; $\mathrm{PA}$, pulmonary artery; $\mathrm{PAH}$, pulmonary arterial hypertension; $\mathrm{PV}$, pulmonary vein; $\mathrm{RA}$, right atrium; RV, right ventricle; SVC, superior vena cava. 


\section{Pulmonary Valve Regurgitation}

CMR is the most accurate method for quantifying pulmonary valve regurgitation (PR) and its secondary hemodynamic consequences, and it plays a crucial role in the timing of reintervention in patients with previous surgery for congenital heart diseases (ie, tetralogy of Fallot). Cine-CMR can show a dark jet of dephasing during diastole extending into the RVOT. PC-CMR quantifies PR using a through-plane positioned just above the valve and the measurement of regurgitant volume is usually direct (Fig. 6). The regurgitant volume or regurgitant fraction and RV EDV have been shown to be highly predictive of the development of symptoms and the need for surgery ${ }^{46,48,51}$ (see Table 5).

\section{Systemic-to-Pulmonary Shunt}

Cine-CMR can provide intracardiac and extracardiac anatomy, size, location, and number of communications between pulmonary and systemic circulations, ventricular volumes and function, and PA dimensions. In atrial septal defect (ASD), cine-CMR can show low-intensity flow jets between the atria. SSFP images in multiple axial and short-axis planes perpendicular to ASD provide an assessment of the defect location and size throughout the cardiac cycle. PCCMR is the noninvasive gold standard for quantifying QP and QS, independent of the location of the shunt. ${ }^{48,51}$ In a PC-cine acquisition with a very low velocity-encoding limit, the flow via the ASD can lead to aliasing and clear demarcation of the defect, allowing measurement of the ASD rims for evaluation of eligibility to percutaneous closure. Ce-MRA details extracardiac shunts ${ }^{48,51}$ (see Table 5).

\section{RIGHT VENTRICLE CARDIOMYOPATHIES Right Ventricle Infarction}

The RV can be involved frequently in inferior acute myocardial infarction (AMI) (up to 50\%) and less often in anterior AMI. Isolated RV AMI is rare $(<3 \%)$. The RV is more resistant to prolonged ischemia than the LV thanks to its more favorable oxygen demand/supply profile; however, lack of $\mathrm{RV}$ recovery is associated with persistent hemodynamic compromise and high mortality. ${ }^{2}$

\section{Role of cardiac magnetic resonance in RV infarction}

In RV infarction, CMR is clinically useful because it allows detailed anatomic and functional assessment of RV and provides tissue characterization. Axial and short-axis cine-CMR can assess accurately eventual increased $\mathrm{RV}$ volume, reduced
$\mathrm{EF}$, and regional function alterations. In acute RV infarction, $T_{2}$ STIR sequences can show RV edema and eventual hemorrhage. LGE-CMR can show, in the RV and frequently in the territory of right coronary artery, subendocardial or transmural LGE, microvascular obstruction (in the acute setting) (Fig. 7), and RV thrombi. LGE of the RV is feasible, but challenging as the RV wall is thin and may require a different time inversion than that used to assess LV LGE. RV LGE has strong prognostic relevance ${ }^{52}$ (see Table 5).

\section{Arrhythmogenic Cardiomyopathy}

Arrhythmogenic cardiomyopathy (ARVC) is a genetically determined cardiomyopathy, characterized by the replacement of the ventricular myocardium by fibro-fatty tissue, from the epicardium toward the endocardium. The RV can be primarily affected with RV dilatation and altered regional and/or global function (see Fig. 1); however, the LV can also be involved, although LV dimensions or function can be normal. Isolated or predominant LV involvement can also be present, usually limited to the subepicardium or midmural layers of the posterolateral wall. ARVC can be a cause of sudden cardiac death due to ventricular fibrillation in young adults, so early diagnosis can be very important. ${ }^{53,54}$

\section{Role of cardiac magnetic resonance in arrhythmogenic cardiomyopathy}

CMR is the imaging modality of choice for early diagnosis of ARVC, as it allows RV multiplanar imaging and tissue characterization. Axial and shortaxis cine-CMR are useful for assessment of RV wall motion abnormalities (regional RV akinesia or dyskinesia or dyssynchronous RV contraction) in addition to increased $R V$ volumes and reduced RV EF, which are the CMR diagnostic criteria included in the last 2010 Task Force Criteria (see Fig. 1). ${ }^{53}$ Axial and short-axis LGE images are useful for assessment of RV and LV LGE. LV LGE (present in up to $25 \%$ of patients with ARVC), instead, has diagnostic value. LGE has mostly a subepicardial/midwall distribution involving especially the posterolateral wall and may be the only sign of LV involvement (Fig. 8). On the basis of LGE, the classification of ARVC has been revised to include the traditional $R V$ form, morpho-functional RV abnormalities with or without RV LGE; LV-dominant form, LV LGE; biventricular form, RV involvement with LV LGE, without LV decreased systolic function; and finally the end-stage form, biventricular involvement characterized by both morphofunctional abnormalities with biventricular heart failure and tissue characterization abnormalities of both ventricles. ${ }^{53-55}$ Currently, no imaging 


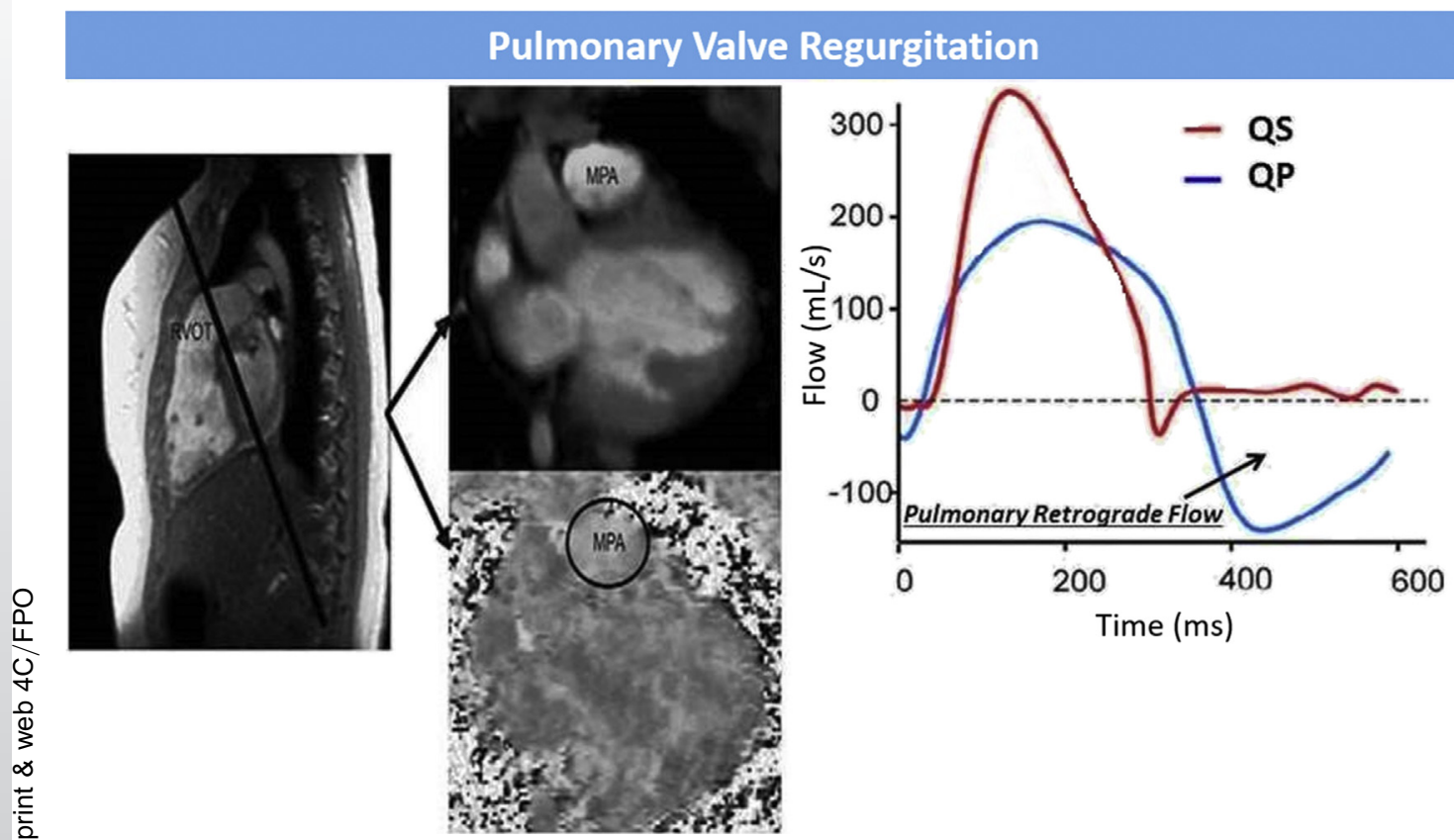

Fig. 6. An example of direct measurement of pulmonary valve regurgitant volume by pulmonary retrograde flow using PC-CMR. PC-CMR, phase contrast cardiac magnetic resonance; QP, pulmonary flow; QS, systemic flow.

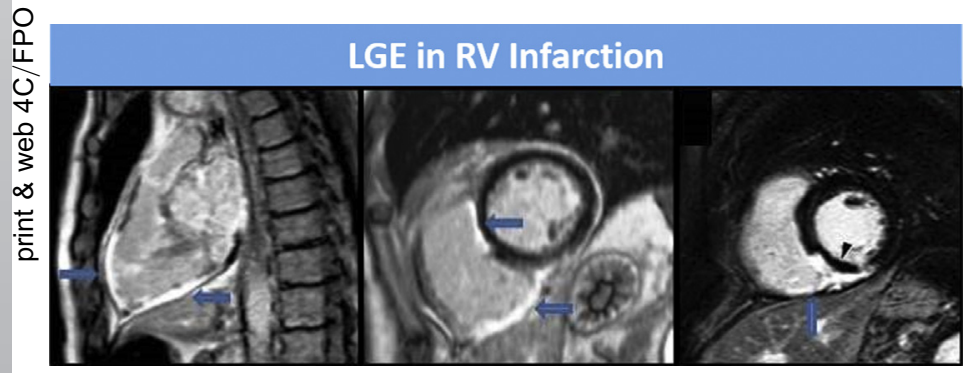

Fig. 7. RV myocardial infarct (blue arrows) with involvement of LV inferior wall and microvascular obstruction (black arrowhead) demonstrated by LGE-CMR. LGE-CMR, late gadolinium enhancement-cardiac magnetic resonance; LV, left ventricle; RV, right ventricle.

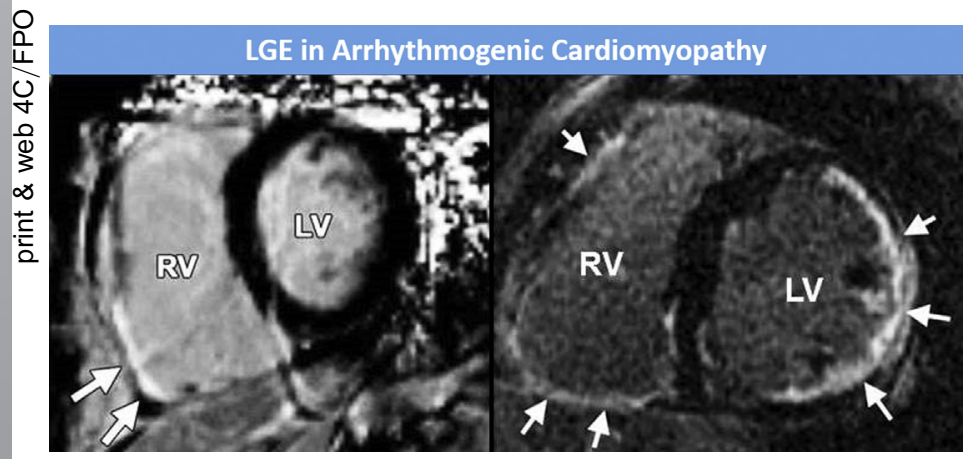

Fig. 8. Examples of LGE in arrhythmogenic cardiomyopathy involving RV and LV (white arrows). LGE, late gadolinium enhancement; LV, left 

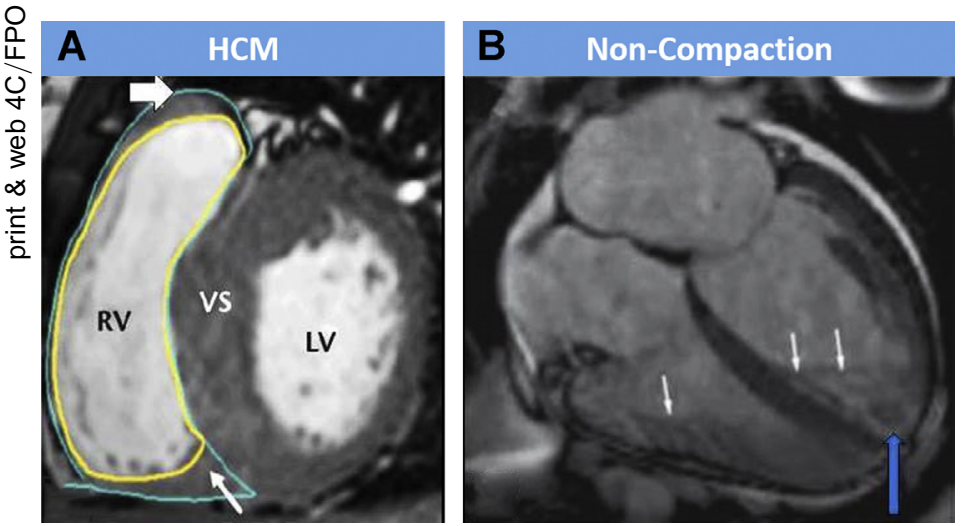

Fig. 9. Short axis showing increased wall thickness in the superior segment and inferior segment (white arrows) of the RV wall in hypertrophic cardiomyopathy $(A)$ and horizontal long axis showing marked trabeculations in both the LV and RV and an LV thrombus (blue arrow) in noncompaction cardiomyopathy (B). HCM, hypertrophic cardiomyopathy; $L V$, left ventricle; RV, right ventricle; VS, ventricular septum.

1856

1857

1858

1859

1860

1861

1862

1863

1864

1865

1866

1867

1868

1869

1870

1871

1872

modality alone (including $\mathrm{CMR}$ ) can diagnose ARVC. ${ }^{53}$ However, CMR evidence of LV involvement is a strong independent predictor of cardiac events in patients with a definite, borderline or possible ARVC diagnosis ${ }^{54,55}$ (see Table 5).

\section{Other Nonischemic Cardiomyopathies}

The RV may also be affected in other nonischemic cardiomyopathies, in which CMR allows early detection of RV involvement ${ }^{1,2}$ (Fig. 9, see Table 5).

\section{SUMMARY}

CMR allows accurate and reproducible multiplanar anatomic and functional assessment of the $\mathrm{RV}$, tissue characterization, and blood flow evaluation of the right heart and pulmonary circulation. It also adds precision to evaluation valvular heart disease and shunt severity.

CMR has shown increasing clinical utility in diagnosis, risk stratification, prognosis, and therapeutic management in disorders of the right heart and pulmonary circulation.

\section{CLINICS CARE POINTS}

- CMR is the gold standard modality for noninvasive RV imaging.

- CMR is useful in diagnosis, risk stratification, prognosis and therapeutic management in disorders of the right heart and pulmonary circulation.

- Limitations of CMR may include low availability, high cost, claustrophobia, safety in patients with ferromagnetic implants and use of gadolinium in patients with severe chronic renal failure.

\section{DISCLOSURE}

Funding: This research did not receive any specific a11 grant from funding agencies in the public, commercial, ornot-for-profit sectors.

\section{REFERENCES}

1. Zhou X, Ferrara F, Contaldi C, et al. Right ventricular size and function in chronic heart failure: not to be forgotten. Heart Fail Clin 2019;15:205-17.

2. Sanz J, Sánchez-Quintana D, Bossone E, et al. Anatomy, function, and dysfunction of the right ventricle: JACC State-of-the-Art Review. J Am Coll Cardiol 2019;73:1463-82

3. Konstam MA, Kiernan MS, Bernstein D, et al. Evaluation and management of right-sided heart failure: a scientific statement from the American Heart Association. Circulation 2018;137:e578-622.

4. Lang RM, Badano LP, Mor-Avi V, et al. Recommendations for cardiac chamber quantification by echocardiography in adults: an update from the American Society of Echocardiography and the European Association of Cardiovascular Imaging. J Am Soc Echocardiogr 2015;28:1-39.e14.

5. Bossone E, Dellegrottaglie S, Patel S, et al. Multimodality imaging in pulmonary hypertension. Can $\mathrm{J}$ Cardiol 2015;31:440-59.

6. Dellegrottaglie S, Ostenfeld E, Sanz J, et al. Imaging the right heart-pulmonary circulation unit: the role of MRI and computed tomography. Heart Fail Clin 2018;14:377-91.

7. Thiele H, Nagel E, Paetsch I, et al. Functional cardiac MR imaging with steady-state free precession (SSFP) significantly improves endocardial border delineation without contrast agents. J Magn Reson Imaging 2001;14:362-7.

8. Galiè N, Humbert M, Vachiery JL, et al, ESC Scientific Document Group. 2015 ESC/ERS Guidelines for the diagnosis and treatment of pulmonary hypertension: The Joint Task Force for the Diagnosis and Treatment
1873

1874

1875

1876

1877

1878

1879

1880

1881

1882

1883

1884

1885

1886

1887

1888

1889

1890

1891

1892

1893

1894

1895

1896

1897

1898

1899

1900

1901

1902

1903

1904

1905

1906

1907

1908

1909

1910

1911

1912 
of Pulmonary Hypertension of the European Society of Cardiology (ESC) and the European Respiratory Society (ERS): Endorsed by: Association for European Paediatric and Congenital Cardiology (AEPC), International Society for Heart and Lung Transplantation (ISHLT). Eur Heart J 2016;37:67-119.

9. Swift AJ, Rajaram S, Condliffe R, et al. Diagnostic accuracy of cardiovascular magnetic resonance imaging of right ventricular morphology and function in the assessment of suspected pulmonary hypertension results from the ASPIRE registry. J Cardiovasc Magn Reson 2012;14:40.

10. Karakus G, Zencirci E, Degirmencioglu A, et al. Easily measurable, noninvasive, and novel finding for pulmonary hypertension: hypertrophy of the basal segment of septomarginal trabeculation of right ventricle. Echocardiography 2017;34: 290-5.

11. Dellegrottaglie S, Sanz J, Poon M, et al. Pulmonary hypertension: accuracy of detection with left ventricular septal-to-free wall curvature ratio measured at cardiac MR. Radiology 2007;243:63-9.

12. Reiter G, Reiter $U$, Kovacs G, et al. Magnetic resonance-derived 3-dimensional blood flow patterns in the main pulmonary artery as a marker of pulmonary hypertension and a measure of elevated mean pulmonary arterial pressure. Circ Cardiovasc Imaging 2008;1:23-30.

13. Sanz J, Kuschnir P, Rius T, et al. Pulmonary arterial hypertension: noninvasive detection with phasecontrast MR imaging. Radiology 2007;243:70-9.

14. Swift AJ, Rajaram S, Condliffe R, et al. Pulmonary artery relative area change detects mild elevations in pulmonary vascular resistance and predicts adverse outcome in pulmonary hypertension. Invest Radiol 2012;47:571-7.

15. Bradlow WM, Assomull R, Kilner PJ, et al. Understanding late gadolinium enhancement in pulmonary hypertension. Circ Cardiovasc Imaging 2010;3: 501-3.

16. Freed $\mathrm{BH}$, Gomberg-Maitland $\mathrm{M}$, Chandra $\mathrm{S}$, et al. Late gadolinium enhancement cardiovascular magnetic resonance predicts clinical worsening in patients with pulmonary hypertension. J Cardiovasc Magn Reson 2012;1:14.

17. Van Wolferen SA, Marcus JT, Boonstra A, et al. Prognostic value of right ventricular mass, volume, and function in idiopathic pulmonary arterial hypertension. Eur Heart J 2007;28:1250-7.

18. Hagger D, Condliffe R, Woodhouse N, et al. Ventricular mass index correlates with pulmonary artery pressure and predicts survival in suspected systemic sclerosis-associated pulmonary arterial hypertension. Rheumatology 2009;48:1137-42.

19. van de Veerdonk MC, Kind T, Marcus J, et al. Progressive right ventricular dysfunction in patients with pulmonary arterial hypertension responding to therapy. J Am Coll Cardiol 2011;58:2511-9.

20. Baggen VJ, Leiner T, Post MC, et al. Cardiac magnetic resonance findings predicting mortality in patients with pulmonary arterial hypertension: a systematic review and meta-analysis. Eur Radiol 2016;26:3771-80.

21. Sato T, Tsujinog I, Oyama-Manabe N, et al. Right atrial volume and phasic function in pulmonary hypertension. Int J Cardiol 2013;168:420-6.

22. Bredfelt A, Rådegran G, Hesselstrand R, et al. Increased right atrial volume measured with cardiac magnetic resonance is associated with worse clinical outcome in patients with pre-capillary pulmonary hypertension. ESC Heart Fail 2018;5:864-75.

23. Gan CT, Lankhaar JW, Westerhof N, et al. Noninvasively assessed pulmonary artery stiffness predicts mortality in pulmonary arterial hypertension. Chest 2007;132:1906-12.

24. Swift AJ, Rajaram S, Capener D, et al. LGE patterns in pulmonary hypertension do not impact overall mortality. JACC Cardiovasc Imaging 2014;7: 1209-17.

25. van Wolferen SA, Boonstra A, Marcus JT, et al. Right ventricular reverse remodeling after sildenafil in pulmonary arterial hypertension. Heart 2006;92: 1860-1.

26. Moon JC, Messroghli DR, Kellman P, et al. Society for Cardiovascular Magnetic Resonance Imaging; Cardiovascular Magnetic Resonance Working Group of the European Society of Cardiology. Myocardial T1 mapping and extracellular volume quantification: a Society for Cardiovascular Magnetic Resonance (SCMR) and CMR Working Group of the European Society of Cardiology consensus statement. J Cardiovasc Magn Reson 2013;15:92.

27. Spruijt OA, Vissers L, Bogaard HJ, et al. Increased native T1-values at the interventricular insertion regions in precapillary pulmonary hypertension. Int $\mathrm{J}$ Cardiovasc Imaging 2016;32:451-9.

28. García-Álvarez A, García-Lunar I, Pereda D, et al. Association of myocardial T1-mapping CMR with hemodynamics and RV performance in pulmonary hypertension. JACC Cardiovasc Imaging 2015;8: 76-82.

29. Shehata ML, Harouni AA, Skrok J, et al. Regional and global biventricular function in pulmonary arterial hypertension: a cardiac MR imaging study. Radiology 2013;266:114-22.

30. Menezes de Siqueira ME, Pozo E, Fernandes VR, et al. Characterization and clinical significance of right ventricular mechanics in pulmonary hypertension evaluated with cardiovascular magnetic resonance feature tracking. J Cardiovasc Magn Reson 2016;18:39.
1970

1971

1972

1973

1974

1975

1976

1977

1978

1979

1980

1981

1982

1983

1984

1985

1986

1987

1988

1989

1990

1991

1992

1993

1994

1995

1996

1997

1998

1999

2000

2001

2002

2003

2004

2005

2006

2007

2008

2009

2010

2011

2012

2013

2014

2015

2016

2017

2018

2019

2020

2021

2022

2023

2024

2025

2026 
31. Padervinskienè L, Krivickiene A, Hoppenot D, et al. Prognostic value of left ventricular function and mechanics in pulmonary hypertension: a pilot cardiovascular magnetic resonance feature tracking study. Medicina (Kaunas) 2019;55:E73.

32. Hanneman K, Kino A, Chenget JY, et al. Assessment of the precision and reproducibility of ventricular volume, function, and mass measurements with ferumoxytol-enhanced 4D Flow MRI. J Magn Reson Imaging 2016;44:383-9.

33. Reiter G, Reiter U, Kovacs G, et al. Blood flow vortices along the main pulmonary artery measured with MR imaging for diagnosis of pulmonary hypertension. Radiology 2015;275:71-9.

34. Kheyfets VO, Schafer M, Podgorski CA, et al. 4D magnetic resonance flow imaging for estimating pulmonary vascular resistance in pulmonary hypertension. J Magn Reson Imaging 2016;44:914-22.

35. Garcia J, Barker AJ, Markl M. The role of imaging of flow patterns by 4D Flow MRI in aortic stenosis. JACC Cardiovasc Imaging 2019;12:252-66.

36. van Ooij $P$, Allen BD, Contaldi $C$, et al. 4D flow MRI and T1-mapping: assessment of altered cardiac hemodynamics and extracellular volume fraction in hypertrophic cardiomyopathy. J Magn Reson Imaging 2016;43:107-14.

37. Barker AJ, Roldan-Alzate A, Entezari P, et al. Fourdimensional flow assessment of pulmonary artery flow and wall shear stress in adult pulmonary arterial hypertension: results from two institutions. Magn Reson Med 2015;73:1904-13.

38. Truong U, Fonseca B, Dunning J, et al. Wall shear stress measured by phase contrast cardiovascular magnetic resonance in children and adolescents with pulmonary arterial hypertension. J Cardiovasc Magn Reson 2013;15:81.

39. Han QJ, Witschey WRT, Fang-Yen CM, et al. Altered right ventricular kinetic energy work density and viscous energy dissipation in patients with pulmonary arterial hypertension: a pilot study using 4D flow MRI. PLoS One 2015;10:e0138365.

40. Itatani K, Miyazaki S, Furusawa T, et al. New imaging tools in cardiovascular medicine: computational fluid dynamics and 4D flow MRI. Gen Thorac Cardiovasc Surg 2017;65:611-21.

41. Tang BT, Pickard SS, Chan FP, et al. Wall shear stress is decreased computational fluid dynamics study. Pulm Circ 2012;2:470-6.

42. La Gerche A, Claessen G, Van de Bruaene A, et al. Cardiac MRI: a new gold standard for ventricular volume quantification during high-intensity exercise. Circ Cardiovasc Imaging 2013;6:329-38.

43. Göransson C, Vejlstrup N, Carlsen J. Exercise cardiovascular magnetic resonance imaging allows differentiation of low-risk pulmonary arterial hypertension. J Heart Lung Transplant 2019;38: 627-35.
44. Knight DS, Kotecha T, Martinez-Naharro A, et al. Cardiovascular magnetic resonance-guided right heart catheterization in a conventional CMR environment-predictors of procedure success and duration in pulmonary artery hypertension. J Cardiovasc Magn Reson 2019;21:57.

45. Ratnayaka K, Faranesh AZ, Hansen MS, et al. Realtime MRI-guided right heart catheterization in adults using passive catheters. Eur Heart J 2013;34:380-9.

46. Rajiah P, Nazarian J, Vogelius E, et al. CT and MRI of pulmonary valvular abnormalities. Clin Radiol 2014; 69:630-8.

47. Garcia MJ. Evaluation of valvular heart disease by cardiac magnetic resonance and computed tomography. In: Otto CM, Bonow RO, editors. Valvular heart disease: a companion to Braunwald's heart disease. 4th edition. Philadelphia: Elsevier; 2014. p. 109-12.

48. Cavalcante JL, von Knobelsdor F, Myerson S. Valve Disease. In: Lombardi M, Plain S, Petersen S, et al, editors. The EACVI textbook of cardiovascular magnetic resonance. 1st edition. Oxford: Oxford University Press; 2018. p. 444-54.

49. Khalique OK, Cavalcante JL, Shah D, et al. Multimodality imaging of the tricuspid valve and right heart anatomy. JACC Cardiovasc Imaging 2019;12:516-31.

50. Martin-Garcia AC, Dimopoulos K, Boutsikou M, et al. Tricuspid regurgitation severity after atrial septal defect closure or pulmonic valve replacement. Heart 2020;106:455-61.

51. Di Salvo G, Miller O, Babu Narayan S, et al. 20162018 EACVI Scientific Documents Committee. Imaging the adult with congenital heart disease: a multimodality imaging approach-position paper from the EACVI. Eur Heart J Cardiovasc Imaging 2018; 19:1077-98.

52. Masci PG, Francone M, Desmet W, et al. Right ventricular ischemic injury in patients with acute STsegment elevation myocardial infarction: characterization with cardiovascular magnetic resonance. Circulation 2010;122:1405-12.

53. Marcus FI, McKenna WJ, Sherrill D, et al. Diagnosis of arrhythmogenic right ventricular cardiomyopathy/ dysplasia: proposed modification of the Task Force Criteria. Eur Heart J 2010;31:806-14.

54. Basso C, Bauce B, Corrado D, et al. Pathophysiology of arrhythmogenic cardiomyopathy. Nat Rev Cardiol 2011;9:223-33.

55. Haugaa KH, Basso C, Badano LP, et al. EACVI Scientific Documents Committee, EACVI Board members and external reviewers; EACVI Scientific Documents Committee, EACVI Board members and external reviewers. Comprehensive multimodality imaging approach in arrhythmogenic cardiomyopathy - an expert consensus document of the European Association of Cardiovascular Imaging. Eur Heart J Cardiovasc Imaging 2017;18: 237-53. 


\section{AUTHOR QUERY FORM}

\begin{tabular}{|c|c|}
\hline 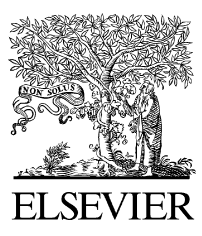 & $\begin{array}{l}\text { Journal: HFC } \\
\text { Article Number: } 888\end{array}$ \\
\hline
\end{tabular}

Dear Author,

Please check your proof carefully and mark all corrections at the appropriate place in the proof (e.g., by using on-screen annotation in the PDF file) or compile them in a separate list. It is crucial that you NOT make direct edits to the PDF using the editing tools as doing so could lead us to overlook your desired changes. Note: if you opt to annotate the file with software other than Adobe Reader then please also highlight the appropriate place in the PDF file. To ensure fast publication of your paper please return your corrections within 48 hours.

For correction or revision of any artwork, please consult http://www.elsevier.com/artworkinstructions.

Any queries or remarks that have arisen during the processing of your manuscript are listed below and highlighted by flags in the proof.

\begin{tabular}{|c|c|}
\hline $\begin{array}{l}\text { Location } \\
\text { in article }\end{array}$ & $\begin{array}{l}\text { Query / Remark: Click on the } Q \text { link to find the query's location in text } \\
\text { Please insert your reply or correction at the corresponding line in the proof }\end{array}$ \\
\hline Q1 & $\begin{array}{l}\text { Please verify your preferred correspondence address to be published and provide any missing } \\
\text { information. Elsevier recommends not using your personal home address. }\end{array}$ \\
\hline Q2 & $\begin{array}{l}\text { For your co-authors, please verify their affiliations and provide a complete address for the affiliations } \\
\text { listed. The address will appear on the footnote of the first page of your article and will be published. Once } \\
\text { again, Elsevier recommends not using personal home addresses. Also, please note that we will send each } \\
\text { contributing author a copy of this issue to their mentioned address. }\end{array}$ \\
\hline Q3 & Is the short title to be used in the running head at the top of each right-hand page correct? \\
\hline Q4 & $\begin{array}{l}\text { Please add a list of Clinics Care Points to the text. Clinics Care Points are a set of evidence-based pearls and } \\
\text { pitfalls relevant to the point of care. Please note, these are different from Key Points. }\end{array}$ \\
\hline Q5 & $\begin{array}{l}\text { Degree abbreviations are verified against a list of known degrees. MACC, MACP are not yet on this list. } \\
\text { Please verify these degrees. }\end{array}$ \\
\hline Q6 & Please provide professional degrees (e.g., PhD, MD) for the author(s) "Gaetano Mirto". \\
\hline Q7 & Are author names and order of authors OK as set? \\
\hline Q8 & $\begin{array}{l}\text { This is how your name will appear on the contributor's list. Please add your academic title, if it is missing, } \\
\text { as well as any other necessary titles and professional affiliations. } \\
\text { CARLA CONTALDI, MD, PhD, Department of Cardiology, University Hospital of Salerno, Salerno, } \\
\text { Italy } \\
\text { FRANCESCO CAPUANO, PhD, Department of Industrial Engineering, Federico II University of } \\
\text { Naples, Naples, Italy } \\
\text { LUIGIA ROMANO, MD, General and Emergency Radiology Division, A Cardarelli Hospital, Naples, } \\
\text { Italy } \\
\text { BRIGIDA RANIERI, PhD, IRCCS SDN, Naples, Italy }\end{array}$ \\
\hline
\end{tabular}


FRANCESCO FERRARA, MD, PhD, Department of Cardiology, University Hospital of Salerno, Salerno, Italy

GAETANO MIRTO, Engineer, Clinical Engineering Division, A Cardarelli Hospital, Naples, Italy SALVATORE REGA, Medical School, Federico II University of Naples, Naples, Italy

ROSANGELA COCCHIA, MD, Cardiology Division, A Cardarelli Hospital, Naples, Italy

ANNA AGNESE STANZIOLA, MD, Department of Respiratory Diseases, Monaldi Hospital, University

"Federico II", Naples, Italy

ELLEN OSTENFIELD, MD, PhD, Department of Medical Imaging and Physiology, Cardiac Imaging, Skåne University Hospital, Lund, Sweden

SANTO DellegROTTAGLIE, MD, PhD, Cardiovascular Magnetic Resonance Laboratory, Hospital Villa dei Fiori, Naples, Italy

EDUARDO BOSSONE, MD, PhD, FCCP, FESC, FACC, Cardiology Division, A Cardarelli Hospital, Naples, Italy

ROBERT O. BONOW, MD, FAHA, FESC, Department of Medicine-Cardiology, Northwestern University Feinberg School of Medicine, Chicago, Illinois, USA

The following synopsis is the one that you supplied, but lightly copyedited. Please confirm OK. Please note that the synopsis will appear in PubMed: Right heart and pulmonary circulation disorders are generally caused by right ventricle (RV) pressure overload, volume overload, and cardiomyopathy, and they are associated with distinct clinical courses and therapeutic approaches, although they often may coexist. Cardiac magnetic resonance (CMR) provides a noninvasive accurate and reproducible multiplanar anatomic and functional assessment, tissue characterization, and blood flow evaluation of the right heart and pulmonary circulation. This article reviews the current status of the CMR, the most recent techniques, the new parameters and their clinical utility in diagnosis, prognosis, and therapeutic management in the right heart and pulmonary circulation disorders.

Q10 If there are any drug dosages in your article, please verify them and indicate that you have done so by initialing this query.

Q11 Correctly acknowledging the primary funders and grant IDs of your research is important to ensure compliance with funder policies. We could not find any acknowledgement of funding sources in your text. Is this correct?

Please check this box or indicate your approval if you have no corrections to make to the PDF file

Thank you for your assistance. 